\title{
Editorial
}

\section{Current scenario of tuberculosis in India}

\author{
J K Mishra ${ }^{1}$, Akhilesh Tiwari ${ }^{1 * *}$ \\ ${ }^{1}$ Dept. of TB and Respiratory Diseases, Institute of Medical Sciences, Banaras Hindu University, Varanasi, Uttar Pradesh, India
}

A R T I C L E I N F O

Article history:

Received 15-12-2021

Accepted 27-12-2021

Available online 16-01-2022
This is an Open Access (OA) journal, and articles are distributed under the terms of the Creative Commons Attribution-NonCommercial-ShareAlike 4.0 License, which allows others to remix, tweak, and build upon the work non-commercially, as long as appropriate credit is given and the new creations are licensed under the identical terms.

For reprints contact: reprint@ipinnovative.com

\section{Introduction}

Tuberculosis (TB) is one of the foremost and transmissible diseases of ailing health. TB is one of the primary causes of death not only in India but worldwide. Before the evolution of Corona Virus (COVID-19), TB was one of the major reasons of fatality and has greater standing level in comparison to HIV/AIDS. The current coronavirus pandemic has had a great impression on the detection and notification of TB cases all over the world. It is quite surprising fact that due to the impact of COVID-19 disease there is a huge and global drop reported in TB cases in year 2020 in comparison to 2019. There are about 7.1 million TB cases during the year 2017 to 2019 whereas, between the years 2019 to 2020 total reported TB cases were about 5.8 million. It shows approximately $18 \%$ of drop in TB cases. ${ }^{1}$ Global reports ${ }^{1}$ evident that out of $6 \mathrm{WHO}$ regions, 5 have clear and relative downfall in TB cases especially in SouthEast Asia and in the West Pacific regions. Only in these two regions the drop of reported TB cases is about $84 \%$ between the years 2019 to 2020. Major contributors of this drop are: India with $41 \%$, Indonesia with $14 \%$, the Philippines with $12 \%$ and China with $8 \%$.

\footnotetext{
* Corresponding author.

E-mail address: kaushik.kaushik777@gmail.com (A. Tiwari).
}

\section{Epidemiology of Tuberculosis}

It is estimated that globally, approximately 9.9 million people were infected and reported TB during the year 2020 . It is about 127 reported cases at the population of 1,00,000. In year 2020, thirty countries contributed about $86 \%$ of reported TB cases worldwide. Out of these thirty countries, eight countries are accountable for two-third number of TB cases including; India with $26 \%$ cases, China $8.5 \%$ cases, Indonesia have $8.4 \%$ cases, the Philippines $6.0 \%$, Pakistan $5.8 \%$, Nigeria $4.6 \%$, Bangladesh $3.6 \%$ and South Africa $3.3 \%$ cases. It is estimation that during the year 2019, there were approximately 1.2 million deaths due HIV and about 1.3 million deaths during the year $2020 .^{2}$ In India, there is about $38 \%$ TB infected deaths due to HIV-negative and about $34 \%$ of deaths due TB, HIV-negative and HIVpositive infected persons. ${ }^{1}$

In 2019, the NTEP achieved a notification rate of 159 TB cases against per lakh of population. In early months of advent of COVID-19 in 2020, this rate was reported as 199 cases per lakh. Although the NTEP missed notifying around 2,40,000 cases of TB during the months of March and April 2020. Due to which TB notifications incidents decreased upto $38 \%$, as compared to January and February 2020. The National TB Elimination program, known significantly for its robust systems, responded promptly, and put his efforts to managed as well as overcome the gaps. In the beginning of the year 2020, with a renewed vigoura result TB case notifications started uprising and an ambitious target of 
notifying 29,99,000 has been achieved.

With focused efforts, the NTEP managed to notify $4,11,242$ Total TB cases by the end of 2020, out of $18,05,670$. There is a rise of $11 \%$ in the TB notifying cases within first two months itself. Apart from Ladakh, Lakshadweep, Mizoram and Sikkim, all other states and UTs showed a decreasein TB Notification rates in March and April in compared to January and February 2020. In May 2020, states took rigorous steps to increase TB case Notifications through Active Case Search and TB-COVID bi-directional screening. Most of the states were successful in showing an increasing trend towards TB Notification.

Nikshay, the surveillance tool of NTEP helped the programme to understand the movement of persons having symptoms of TB. It is also helpful in making comparative analysis with previous years when there was no COVID-19 pandemic in terms of care seeking behaviour and diagnosing locations. Delhi (456/lakh), Chandigarh (366/lakh) and Puducherry (185/lakh) still had the highest TB Notification rates. These states/UTs mainly provide diagnostic services to population beyond their borders. ${ }^{2}$

TB affects people of all genders and all age groups, but the men, accounted for $61.7 \%$ of all TBcases in 2020 . Children (0-14 years) formed $5.65 \%$ of total TB cases. The Age Sex Notification distribution shows that there is a preponderance of TB (38\% of total) among the age group 15 -30 years for both males and females. However, the southern states of Kerala, Karnataka, Andhra Pradesh and Tamil Nadu, and in two North-eastern states of Tripura and Manipur, the proportion of TB in 15-30 years age group is between the range of $18 \%$ to $29 \%$. The proportion of $\mathrm{TB}$ cases in the age group 0 - 14 years is below the National average of $6 \%$ in these states. In the transgender population, 970 were notified with TB, out of which 64 (6.6\%) belonged to age group $0-14$ years.

\section{Effect of COVID-19 on Tuberculosis}

In 2019 the reported cases were 23,28,338, out of which reported treatment success was $82 \%(\mathrm{~N}=19,05,920)$, death rate was $4 \%$, and lost to follow-up was $4 \%$. Treatment failure and regimen change after initiation of treatment was together about $3 \%$, and an overall of $9 \%$ cases were not evaluated after the notification. Country has reported 24 lakh TB notifications in the year 2019 which is highestever annual TB notification. The situation that arose due to COVID-19 pandemic and nationwide lockdown, literally broke the rising trend of TB notifications in the year2020. However, India has notified 18 lakh TB notifications in the year 2020 which shows the decline of $25 \%$ from notification in 2019. Approximately 17.10 lakh(95\%) TB patients put on treatment. The proportion of TB patients put on treatment out of notification, remains same in the year 2020 in compared to 2019. Under the first National Strategic Plan for Retreatment, TB patients are $84 \%$. The country has introduced and rapidly expanded CBNAAT Treatment success rate in TB-HIV co-(GeneXpert), UDST as a national policy and infected patients is now $69 \%$.

In 2020, 49,679 MDR/RR-TB cases were diagnosed and 42,505 were put on treatment. COVID has affected DRTB notification also and reduced $25 \%$ DR-TB notification compared to 2019. 1232 XDR-TB and $13384 \mathrm{H}$ mono/poly DR-TB patients were diagnosed. Further, based on SLDST results and other eligibility criteria, 10,489 M/DR-TB patients were initiated on newer drug containing regimen (including 10,140 on $\mathrm{Bdq}$ and 349 on Dm containing regimen). 14,735 patients were enrolled on all oral longer regimens.

Tuberculosis (TB) and HIV are major public health problems globally and particularly in India. These two diseases are leading causesof morbidity and mortality among all other infectious diseases. In 2019, India accounted for estimated 71000 (49000-98000) incident HIV TB co-infected patients against the previous estimate of 92000 HIV TB co-infected patients (63000-126000) in 2018 (WHO's Global TB report 2020). India ranks second in the world as far as TB-related mortality is concerned. About nine per cent of the global burden of HIV associated TB is borne by India. Every year, 11,000 Indians die due to HIVassociated TB. ${ }^{3}$

Paediatric Tuberculosis (TB) is one of the ten major causes of mortality globally among the children (population age less than 15 years). It is an estimation that in 2019 about 12 lakh children became ill with TB. Out of this estimation, $1.9 \%$ of children died because of TB (including children with HIV associated TB). In India, about 3,42,000 incident cases of pediatric TB are estimated to occur every year accounting for $31 \%$ of the global burden and $13 \%$ of the overall $\mathrm{TB}$ burden in the country. In India, although paediatric TB is estimated to be approximately $10 \%$ of total incident cases, only 5.6\% (102090/1805670) of the total cases reported to the National TB Elimination Programme (NTEP) in 2020 are children, and this proportion has remained almost similar over the last several years.

Since last one-and-half year, when the Pandemic of COVID-19 evolved, the health sector is totally engaged in the management of COVID-19 related disease. COVID-19 has adversely affected all other non-COVID activities as all resources have been directed to the COVID management and obviously TB control is no exception. There are various factors who contributed to force the NTEP to focus on TB control in India. These factors include; imposing lockdown to restrict the growth of infection, restricted movement of people, psychological fear of contacting the disease in health-care facilities, utilization of diagnostic facilities like CBNAAT machines for COVID work, conversion of hospitals for care of these patients, financial diversion, and similar reasons. Due to the nation-wide lockdown TB case notifications decreased by $50 \%$ in both public and private 
sectors between the months of March and April 2020. Though, reports show a little recovery at the end of June 2020 but it was far away from March levels. With the advent of second wave of COVID-19 (more extensive and fatal), things have again gone to haywire. Global TB report $2020^{3}$ identified two major key factors: per capita GDP and under nutrition as the catalyst to worsen the scenario. It also suggests that the number of people developing TB could increase by more than 1 million per year in the following years. Loss of income or unemployment could also increase the proportion of people with $\mathrm{TB}$ and $\mathrm{HHs}$ facing catastrophic costs. ${ }^{4}$

\section{Conflict of Interest}

None.

\section{References}

1. Global Tuberculosis Report; 2021. Available from: https://www.who. int/publications/i/item/9789240037021.

2. India TB annual Report; 2021. Available from: https://tbcindia.gov.in/ showfile.php?lid=3587.

3. Available from: https://www.researchgate.net/profile/JyotiShrivastava-3/publication/350840582_JLPRR-08-00246_6_1/links/ 607592b04585151ce17ff4f3/JLPRR-08-00246-6-1.pdf.

4. Behera D. TB control in India in the COVID era. Indian J Tuberc. 2021;68(1):128-33.

\section{Author biography}

J K Mishra, Professor

Akhilesh Tiwari, Senior Resident

Cite this article: Mishra JK, Tiwari A. Current scenario of tuberculosis in India. J Community Health Manag 2021;8(4):150-152. 